\title{
NUMERICAL SIMULATION OF FORMING TITANIUM THIN-WALL PANELS WITH STIFFENERS
}

\author{
Janina Adamus' ${ }^{1}$, Julita Winowiecka' ${ }^{1}$, Marcin Dyner' ${ }^{2}$, Piotr Lacki ${ }^{2}$ \\ 1 Czestochowa University of Technology, Dabrowskiego 69, 42-201 Czestochowa, Poland, e-mail: \\ janina.adamus@gmail.com, julita.winowiecka@gmail.com \\ 2 CHIRMED Manufacturer of Surgical and Medical Instruments, Mstowska 8A, 42-240 Rudniki-Czestochowa, \\ Poland, e-mail:m.dyner@chirmed.pl, piotr@lacki.com.pl
}

Received: 2017.10 .06

Accepted: 2018.02.01

Published: 2018.03.01

\begin{abstract}
Due to the increase in the application of titanium components made of thin titanium sheets, in the work titanium panels made of $4 \mathrm{~mm}$ thick sheets are analysed. To increase the rigidity of the panels, some cross-shaped stiffeners were made. Such panels enable a reduction in weight while maintaining the existing strength of the drawn parts. Three kinds of commercially pure titanium are considered: Grade 1, 2 and 3. Numerical calculations were performed with PamStamp 2G based on the finite element method. The basic mechanical and technological properties of the analysed sheets, which are necessary for numerical modelling, were determined by static tensile testing. The friction coefficient was assumed based on the literature. On the basis of the performed numerical analyses, it was stated that the proper forming of panels with stiffeners depends not only on the drawability of the sheets but also on the technological parameters such as blank holder force and frictional conditions.
\end{abstract}

Keywords: sheet, commercially pure titanium, sheet-metal forming, stiffeners, numerical simulation

\section{INTRODUCTION}

Titanium sheets are used in many areas of our life. They have a well-established position in aviation and aerospace $[7,9,10,30]$. Titanium sheets are increasingly used in the automotive $[13,14,18,19]$ and medical industries [17, $20,21,25]$, and recently also in civil engineering [5] as well as in offshore structures [22, 28]. The growing interest in the use of titanium sheet products is due to the excellent properties of titanium, including high specific strength (strengthto-weight ratio) and good resistance to most corrosive environments. In addition, biocompatibility [16, 27], allowing the correct functioning of titanium implants in living organisms, is well recognized in medicine as well as osteointegration with bone tissue, which creates good conditions for a durable and stable junction between an implant with the bone. The wide range of architectural capabilities associated with titanium anodic oxidation are of interest to civil engineering. Thanks to light interference phenomena taking place at the titanium-oxide-air interfaces with continuous changing of the oxide film thickness, it is possible to obtain a gradation colour looking like rainbow $[12,29]$. Anode oxidation, besides titanium coloration, has the effect of increasing the corrosion resistance of titanium products. Numerous titanium drawn parts are used as different kinds of casings. Civil engineering, like the aerospace industry, uses titanium's resistance to high temperatures for the production of firewalls. The materials used in cover elements are required to ensure structural stability and to protect the users from the effects of heat and flame for a sufficient time to leave a room at the risk of fire. According to US Federal Aviation Regulations (FAR PART 
23.1191), titanium sheets with a thickness of 0.016 inch (i.e. $\sim 0.4 \mathrm{~mm}$ ) are one of the materials that can be used for covers, including firewalls, without special testing for creep-resistance and heat-resistance Since shielding components do not require high strength, pure titanium sheets are used to produce these parts. The tensile strength of pure titanium sheets ranges from $\mathrm{R}_{\mathrm{m}}=240 \mathrm{MPa}$ for commercially pure titanium Grade 1 to about $550 \mathrm{MPa}$ for titanium Grade 4. As the amount of impurities increases, the mechanical properties of titanium increase, at the expense of reducing its plasticity. Grade 1 and 2 titanium sheets have relatively good drawability, while other titanium grades, especially titanium alloys, are characterised by low drawability and they are prone to springback after unloading. Additionally, titanium has low tribological properties, which appears as the formation of titanium protrusions on the steel forming tools and galling [6]. It is particularly difficult to shape almost flat panels of thin titanium sheets. To stiffen large flat surfaces and reduce the tendency to warp, shallow embossing is performed on the panels. In addition, stiffening ribs reduce the sheet thickness, which is especially important due to the reduced mass of the shaped parts, without lowering their mechanical strength. Unfortunately, during their forming deformations often appear which impede the assembly of panels and their subsequent exploitation. Problems related to shaping titanium alloy sheets including numerical modelling are discussed in $[8,11,15,25]$. The present work is a continuation of the former authors' research [1 - 4] aimed at developing guidelines for forming titanium panels with stiffeners. The work analysis the cold forming of thin-wall panels with stiffeners in order to obtain optimum shaping parameters so that their flat surfaces will not deform. The analyses are performed with a commercial program PAMStamp 2G v. 2012 based on FEM [26], which is dedicated to supporting the design of sheet-metal forming, including tool design, formability analyses, try-out validation and prediction of springback after unloading.

\section{NUMERICAL ANALYSES}

The numerical analysis concerns forming panels with cross-shaped stiffeners as shown in Figure 1. Panels made of three grades of pure titanium: Grade 1, Grade 2 and Grade 3 are analysed. $0.4 \mathrm{~mm}$ thick sheets were used for their construction.

The chemical composition of the analysed commercially pure titanium grades is given in Table 1 . The mechanical and technological parameters, which are essential for numerical analyses, were determined in a static tensile test according to PN-EN ISO 6892-1:2016-09.

\section{Numerical model}

To simulate the stamping processes of panels with stiffeners, the surface models (Figure 2) of the real tools were prepared using the Catia v5 program. Then these models were imported to the appropriate PAMSTAMP $2 \mathrm{G}$ module.

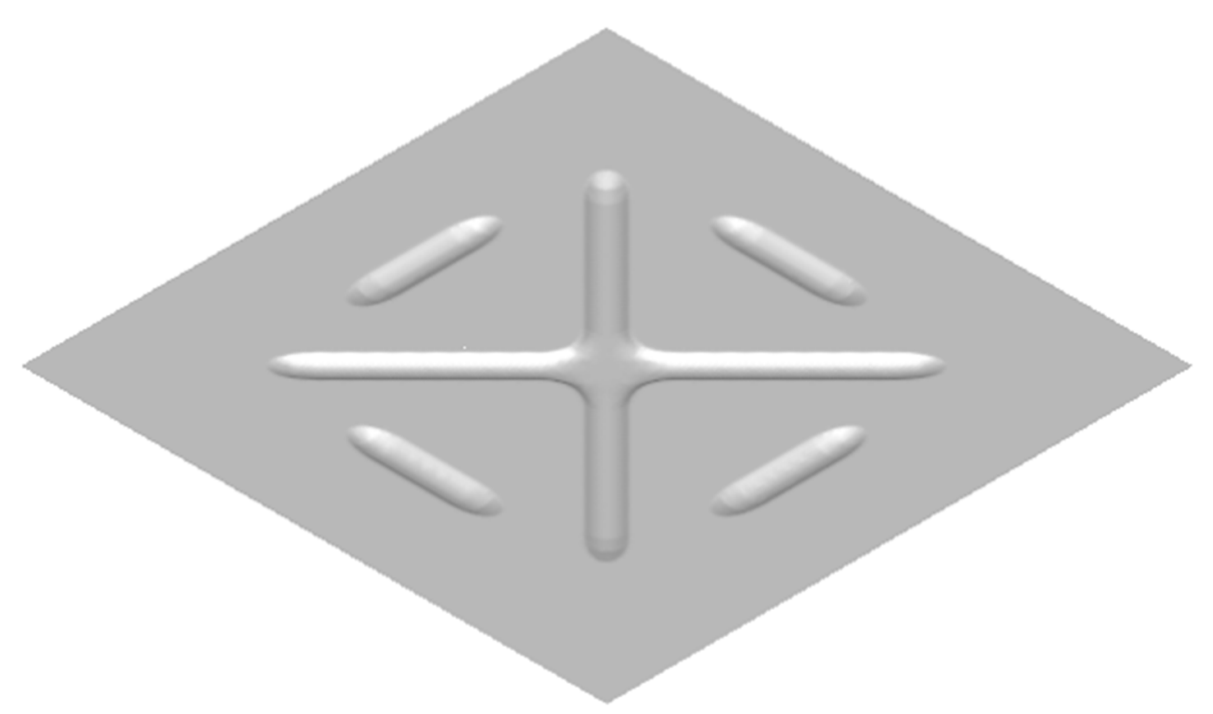

Figure 1. View of part of shielding component with cross-shaped stiffeners 
Table 1. Chemical composition of analysed titanium sheets

\begin{tabular}{|c|c|c|c|}
\hline Element & Material & Grade 1 & Grade 2 \\
\hline $\mathrm{C}$ & $0.080 \div 0.008$ & $0.007 \div 0.006$ & $0.014 \div 0.016$ \\
\hline $\mathrm{Fe}$ & $0.200 \div 0.040$ & 0.140 & $0.120 \div 0.130$ \\
\hline $\mathrm{N}$ & $0.002 \div 0.050$ & $0.006 \div 0.008$ & $0.007 \div 0.010$ \\
\hline $\mathrm{O}$ & $0.200 \div 0.070$ & 0.100 & 0.210 \\
\hline $\mathrm{Ti}$ & rest & rest & rest \\
\hline
\end{tabular}

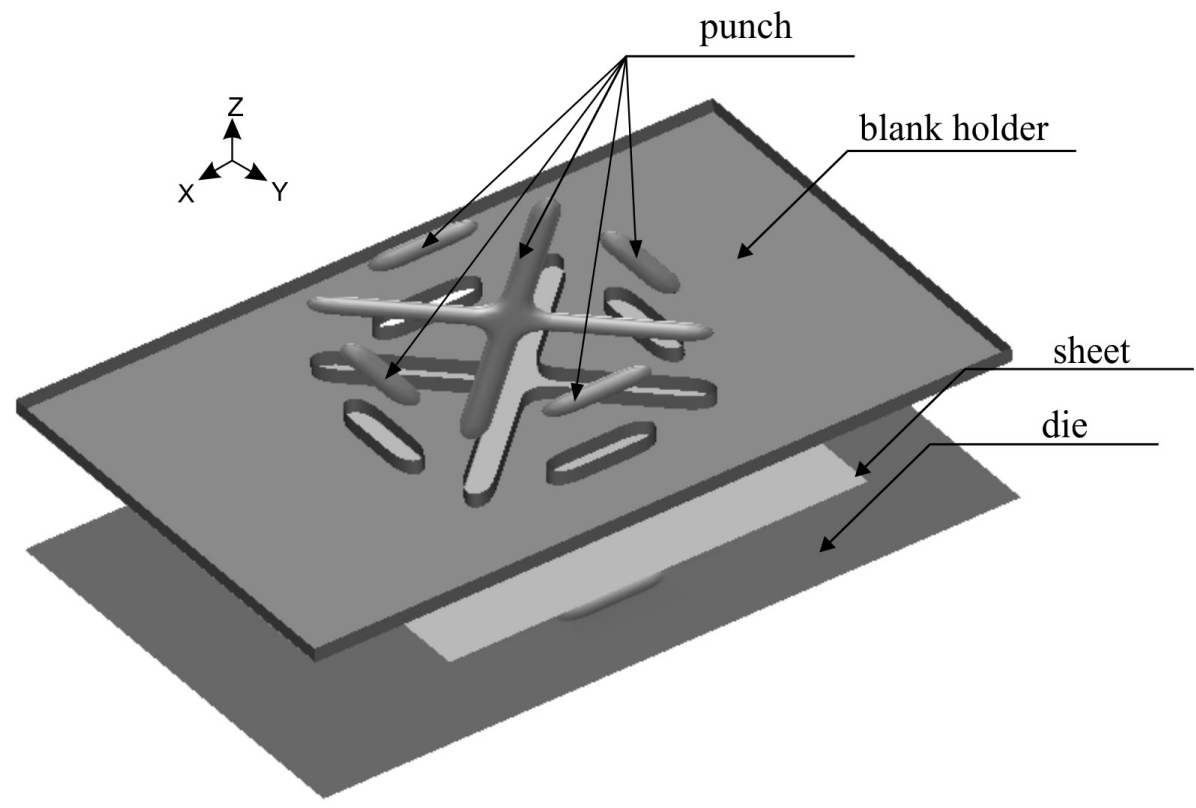

Figure 2. Surface model of tools for forming thin-wall panels with cross-shaped stiffeners

Four-node shell elements were used to model both the tools and sheet. The appropriate boundary conditions were assigned to each tool part, namely:

- the die was deprived of all degrees of freedom

- the punch and the blank holder can move in the direction of the $\mathrm{Z}$ axis thanks to applying a velocity vector to the punches and a force to the blank holder

- the blank has all degrees of freedom.

The deformed materials (sheets) were defined as anisotropic, considering Hill 48's yield criterion. The strain-stress curves for the analysed sheets were described according to Hollomon's law $\sigma=\mathrm{K} \cdot \varepsilon n$, where: $\mathrm{K}-$ the material constant, $\mathrm{n}$ - the strain hardening coefficient. The material properties assumed in the material models are given in Table 2. All the properties were determined experimentally in the static tensile test.

The strain-stress curves in three characteristic directions: $0^{\circ}, 45^{\circ}$ and $90 \mathrm{o}$ to the rolling direction for all the analysed sheets are presented in
Figure 3, while a graphical representation of the r-values is presented in Figure 4.

All the analysed sheets are characterised by both normal and planar anisotropy. Although high normal anisotropy shows that a sheet is resistant to material thinning, i.e. is resistant to tensile in the normal direction to the sheet surface, the planar anisotropy, which ranges from -1.612 to -0.288 , is especially unfavourable in sheet-metal forming because it is a reason for uneven metal flow.

\section{Numerical simulation results}

Based on the results of forming panels with two stiffeners, which are presented in [22-24], it was decided that the present numerical analyses will be performed for panels with cross-shaped stiffeners deformed in dry conditions without any lubrication. Previous studies show that the forming process of thin-wall panels with stiffeners should be performed in dry conditions with the smallest blank holder force, but one that provides the correct course of the process and the assumed 
Table 2. Material properties assumed in numerical simulations

\begin{tabular}{|c|c|c|c|c|}
\hline \multicolumn{2}{|c|}{\begin{tabular}{|ll} 
Parameter & Material \\
\end{tabular}} & Grade 1 & Grade 2 & Grade 3 \\
\hline \multicolumn{2}{|c|}{ Young's modulus E [GPa] } & 116.95 & 102.84 & 106.21 \\
\hline \multicolumn{2}{|c|}{ Yield point $R_{e}[\mathrm{MPa}]$} & 291.03 & 344.25 & 515.50 \\
\hline \multicolumn{2}{|c|}{ Poisson's coefficient v [-] } & 0.34 & 0.37 & 0.37 \\
\hline \multicolumn{2}{|c|}{ Density $\rho\left[\mathrm{kg} / \mathrm{m}^{3}\right]$} & 4510 & 4500 & 4510 \\
\hline \multicolumn{2}{|c|}{ Material constant $\mathrm{K}$ [MPa] } & 533.57 & 628.45 & 811.87 \\
\hline \multicolumn{2}{|c|}{ Strain hardening coefficient $\mathrm{n}[-]$} & 0.106 & 0.098 & 0.089 \\
\hline \multirow{3}{*}{ r-value } & $\mathrm{r}_{0}$ & 2.248 & 2.059 & 0.795 \\
\hline & $r_{90}$ & 2.596 & 4.259 & 2.293 \\
\hline & $r_{45}$ & 4.034 & 3.447 & 2.445 \\
\hline
\end{tabular}

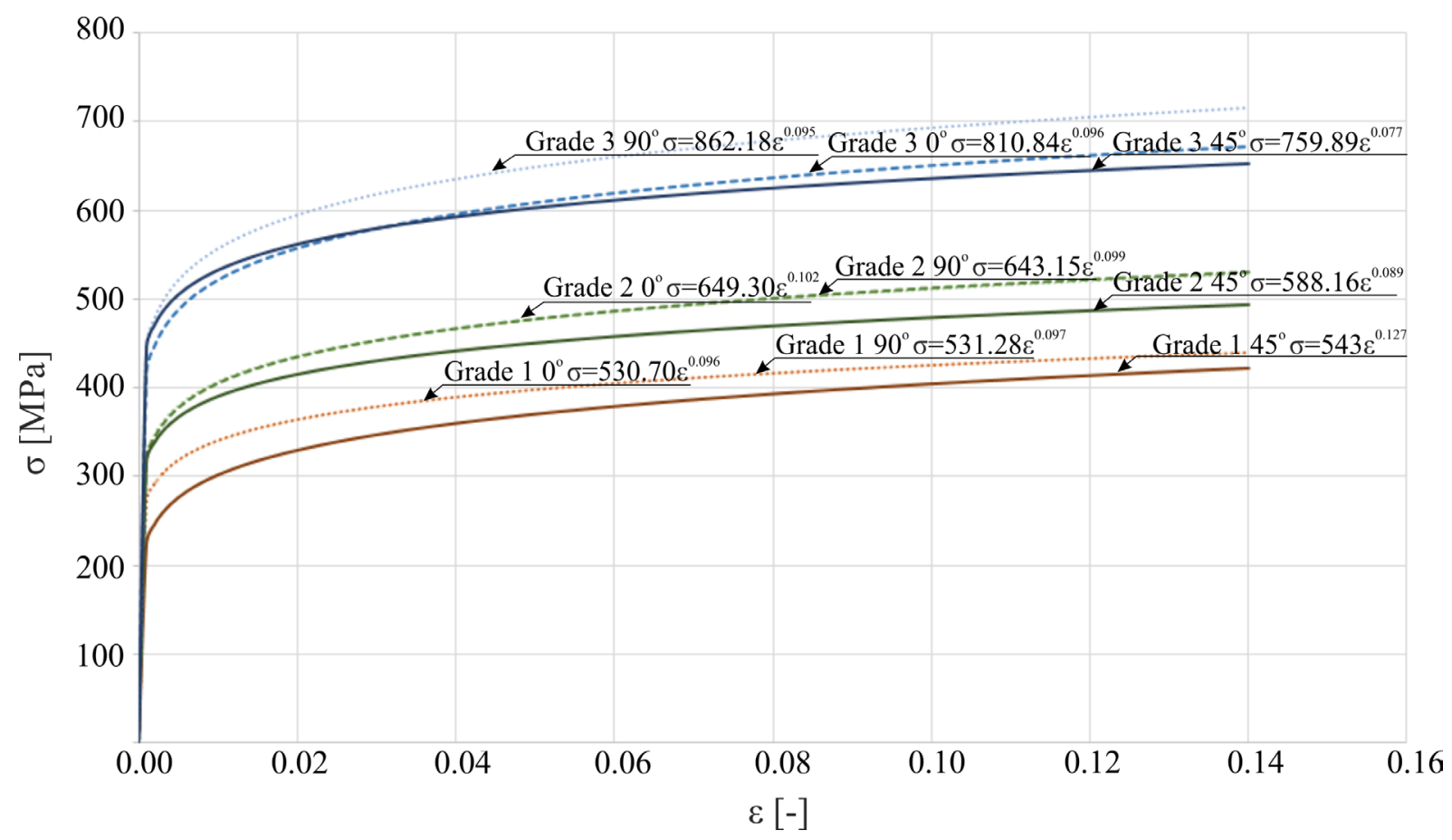

Figure 3. Stress-strain curves for analysed titanium sheets

quality of the stiffeners. The technological parameters, such as the friction coefficient or blank holder force, should be selected so that the stiffeners are formed only by stretching without drawing material from the flat part of the panel into the die cavity. This will prevent warping and bending of the panels and in turn it will make panel assembly easier and reduce the sound effects accompanying any eventual deformation of nearly flat thin-wall panels. In the numerical calculations, according to [25], friction coefficient $\mu=0.4$ was assumed for the technically dry conditions.

The following blank holder forces were applied: $600,800,1000$ and $1200 \mathrm{kN}$. As in the case of panels with two stiffeners, the plastic strains and sheet thinning as well as the width of the panels after forming (in two mutually perpendicular directions $\mathrm{X}$ and $\mathrm{Y}$ ) and springback after unloading are analysed. A summary of the numerical simulation results of forming titanium panels for all titanium grades: Grade 1,2 and 3 is given in Table 3.

The thickness and plastic strain distributions, for example, for forming a Grade 1 titanium panel with the blank holder force of $1200 \mathrm{kN}$ are presented, respectively, in Figures 5 and 6.

Analysis of the numerical calculation results shows that the uniform thickness distribution in the flat part of the panel (Figure 5) was obtained for all the analysed blank holder forces. In the spots of the greatest sheet thinning occurring in the area of the stiffeners, the sheet thickness for 


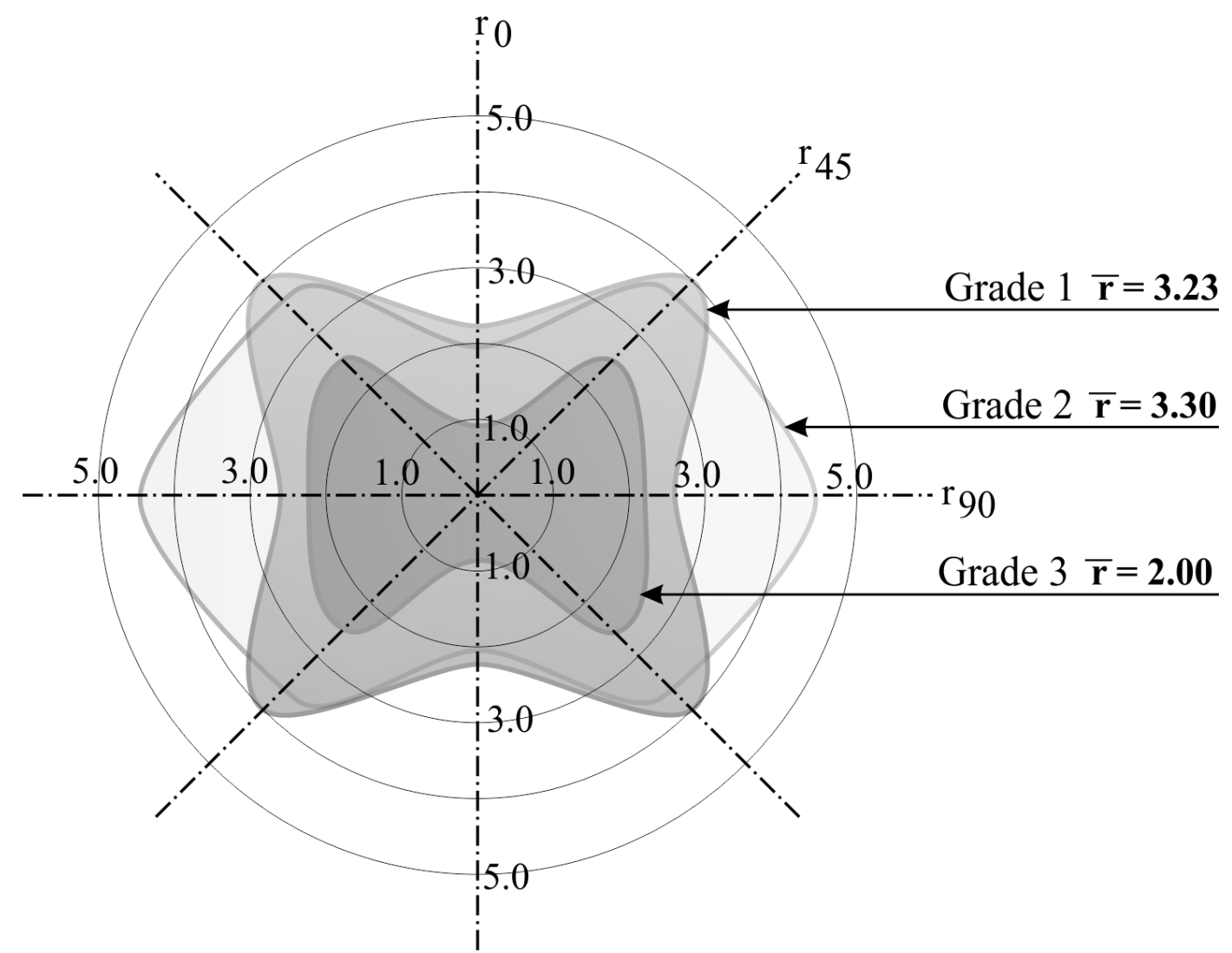

Figure 4. r-values depending on direction of loading in-plane $\left(0^{\circ}, 45^{\circ}\right.$ and 900 to rolling direction $)$ for titanium: a) Grade 1, b) Grade 2, c) Grade 3

Table 3. Numerical results of forming titanium panels with cross-shaped stiffeners

\begin{tabular}{|c|c|c|c|c|c|c|}
\hline \multirow[b]{2}{*}{ Material } & \multirow[t]{2}{*}{$\begin{array}{c}\text { Blank } \\
\text { holder force } \\
{[\mathrm{kN}]}\end{array}$} & \multirow[t]{2}{*}{$\begin{array}{l}\text { Min thickness } \\
{[\mathrm{mm}]}\end{array}$} & \multirow[t]{2}{*}{$\begin{array}{c}\text { Plastic strain } \\
{[-]}\end{array}$} & \multicolumn{2}{|c|}{$\begin{array}{l}\text { Decrease in panel width } \\
\text { [mm] } \\
\text { in direction }\end{array}$} & \multirow[t]{2}{*}{ Springback [mm] } \\
\hline & & & & axis $X$ & axis $Y$ & \\
\hline \multirow{4}{*}{ Grade 1} & 600 & 0.360 & 0.143 & 0.002 & 0.002 & 8.995 \\
\hline & 800 & 0.358 & 0.151 & 0.001 & 0.001 & 8.986 \\
\hline & 1000 & 0.357 & 0.154 & 0.000 & 0.000 & 8.955 \\
\hline & 1200 & 0.356 & 0.158 & 0.000 & 0.000 & 8.857 \\
\hline \multirow{4}{*}{ Grade 2} & 600 & 0.365 & 0.130 & 0.015 & 0.037 & 10.563 \\
\hline & 800 & 0.364 & 0.137 & 0.002 & 0.003 & 10.208 \\
\hline & 1000 & 0.362 & 0.144 & 0.001 & 0.001 & 10.488 \\
\hline & 1200 & 0.361 & 0.149 & 0.000 & 0.000 & 10.113 \\
\hline \multirow{4}{*}{ Grade 3} & 600 & 0.361 & 0.120 & 0.021 & 0.086 & 30.801 \\
\hline & 800 & 0.359 & 0.130 & 0.002 & 0.022 & 19.847 \\
\hline & 1000 & 0.355 & 0.137 & 0.001 & 0.003 & 17.311 \\
\hline & 1200 & 0.353 & 0.142 & 0.000 & 0.001 & 17.228 \\
\hline
\end{tabular}

forming with blank holder force $\mathrm{Fb}-\mathrm{h}=1200 \mathrm{kN}$ is $0.356 \mathrm{~mm}$. The greatest thinning appears in the lower part of the stiffeners, while at the top of them the thinning is slight. During forming with force $\mathrm{Fb}-\mathrm{h}=1200 \mathrm{kN}$, there are also the greatest plastic strains of 0.158 (Figure 6). Although there was no reduction in panel width in the $\mathrm{X}$ and $\mathrm{Y}$ directions $(0.000 \mathrm{~mm})$, the numerical simulations indicate that unloading the panels causes significant springback, especially for the panels made of Grade 3. The change in panel width is defined as the difference between the initial width of the blank and the final width of the panel. The smallest springback of $8.857 \mathrm{~mm}$ was observed after forming the Grade 1 panel, which was formed with blank holder force Fb-h=1200 kN. Spring- 


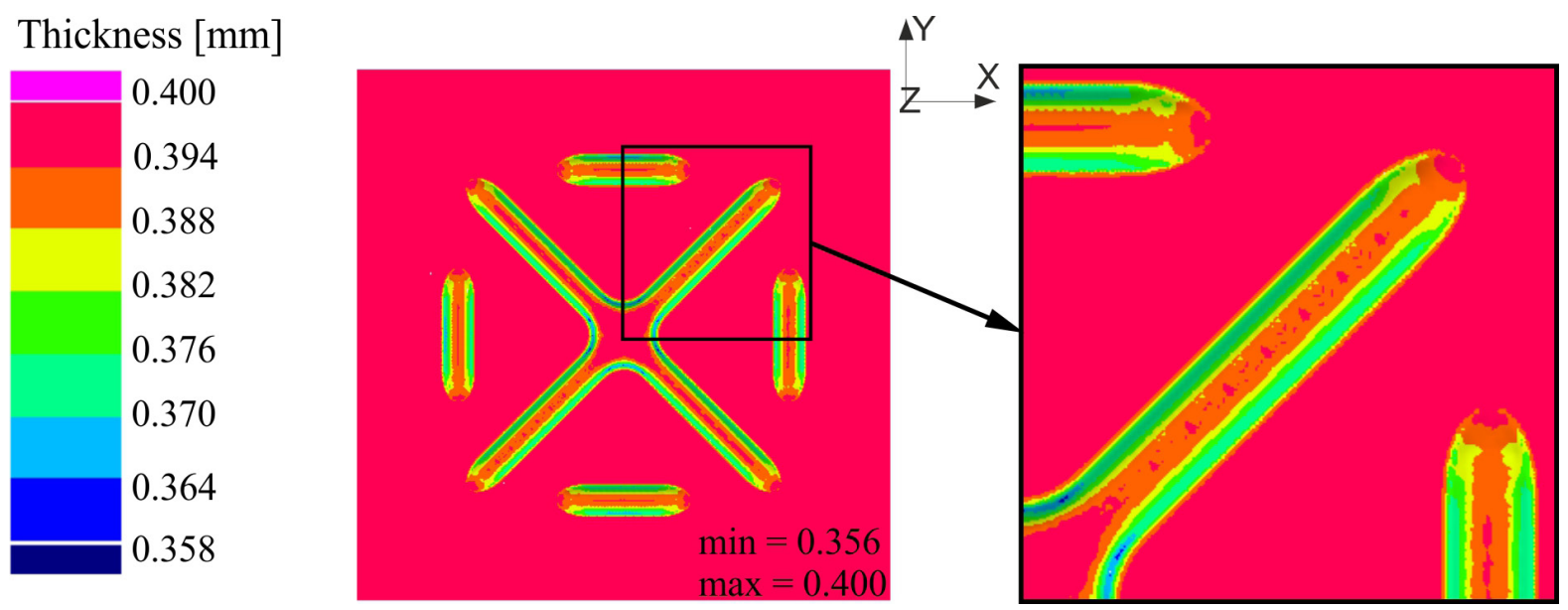

Figure 5. Thickness distribution in Grade 1 titanium drawn part: $\mu=0.4, \mathrm{Fb}-\mathrm{h}=1200 \mathrm{kN}$
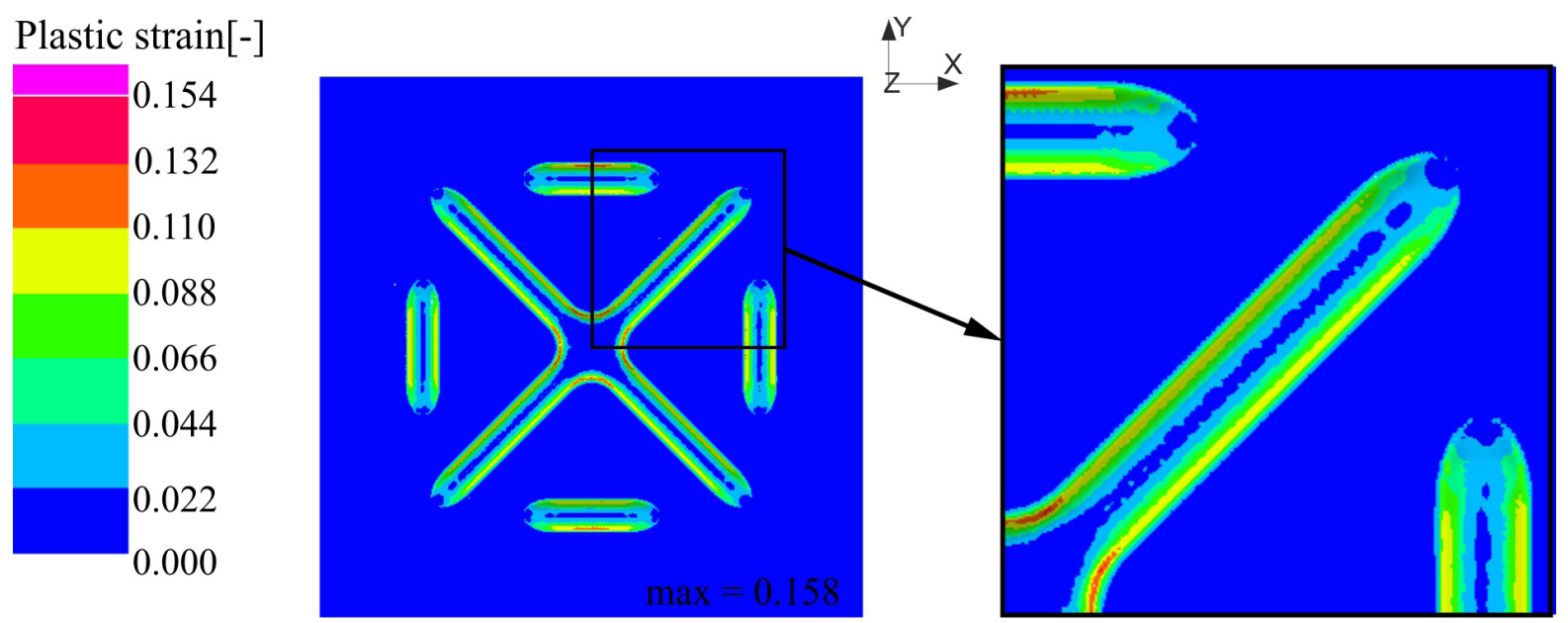

Figure 6. Plastic strain distribution in Grade 1 titanium drawn part: $\mu=0.4, \mathrm{Fb}-\mathrm{h}=1200 \mathrm{kN}$

back is defined as the numerical distance between the corresponding nodes of the reference element and the unloaded element measured in millimetres (see Figure 7). The springback, for example, in the Grade 1 titanium panel after unloading is presented in Figure 8.

It results from the fact that both the thickness and plastic strains in the area of the stiffeners are not even and they are not symmetrically distributed. The most likely cause of such a distribution of plastic strains and sheet thickness is the large planar anisotropy and placement of the stiffeners in the panel.

The influences of blank holder force and kind of material on the maximal plastic strains and springback value are presented in Figure 9 and 10 , respectively.

Analysis of the numerical calculation results shows that the higher the blank holder force, the lower the springback is. It is because a lower volume of the material from the flat part of the panels is pulled into the die cavities, hence the stiffeners are mostly formed by stretching. Too little pressure allows the material to slide out of the blank holder and flow into the die cavity, as a result the panel width decreases. The panel undergoes considerable distortion and starts to flex. The amount of blank holder force needed to form the stiffeners significantly depends on the deformed material. This is clearly visible on the example of the Grade 3 titanium panel for which even a blank holder force of $1200 \mathrm{kN}$ is not enough to form the panels. The springback value reaches $\sim 17 \mathrm{~mm}$. When there is no possibility to increase the friction coefficient and the blank holder force, it is necessary to reconsider the shape, size and location of stiffeners in the panel, because the authors noticed that the tendency of the panels to flex and "wave" is also influenced by how the stiffeners are placed in the panels. However, to determine the optimal distribution of stiffeners in panels, further numerical analyses are required. 


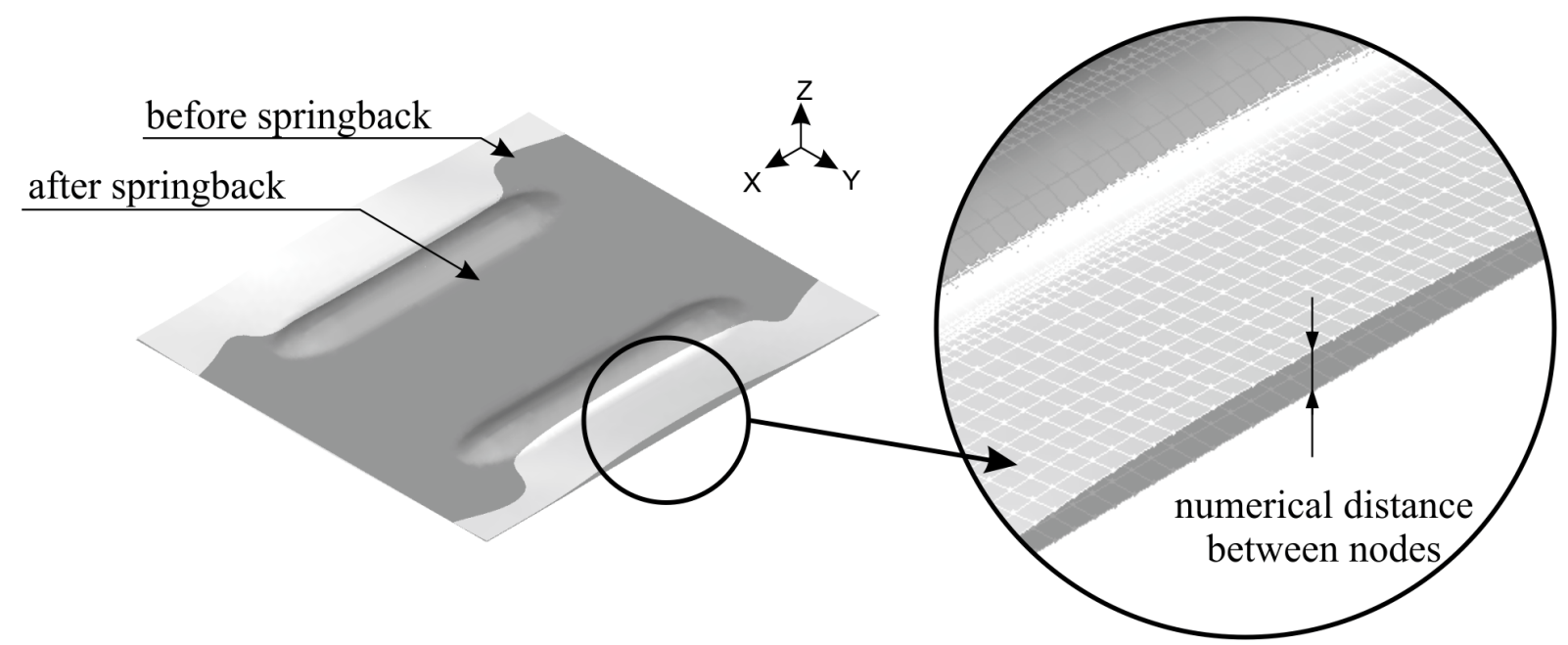

Figure 7. Springback definition in numerical simulation

Distance between nodes [mm]
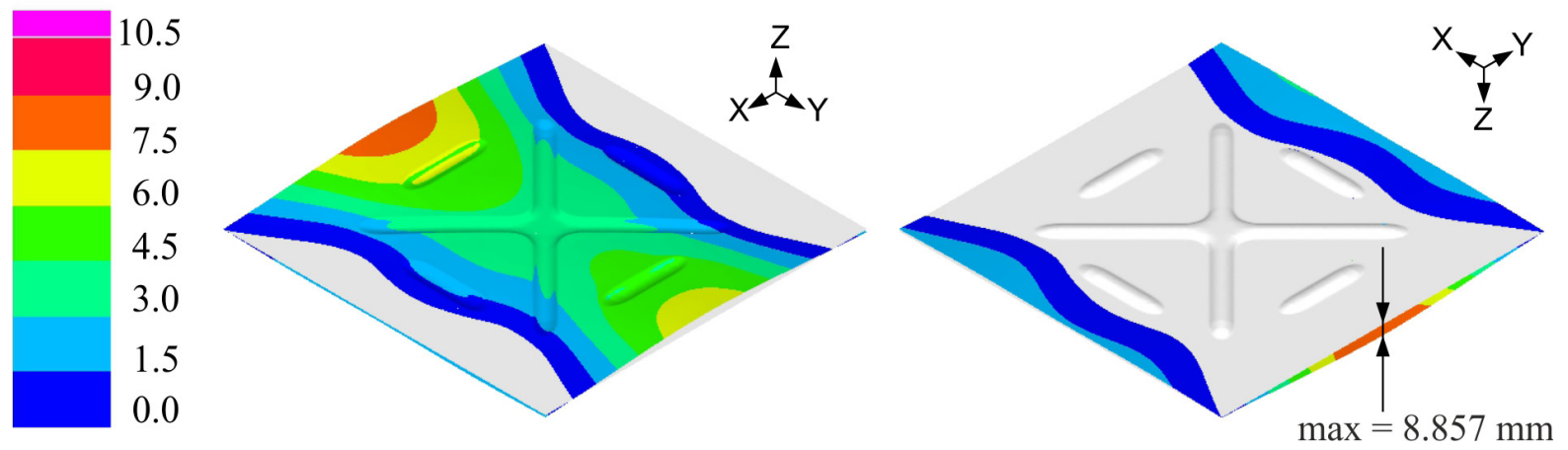

Figure 8. Springback in Grade 1 titanium drawn part: $\mu=0.4$. $F b-h=1200 \mathrm{kN}$

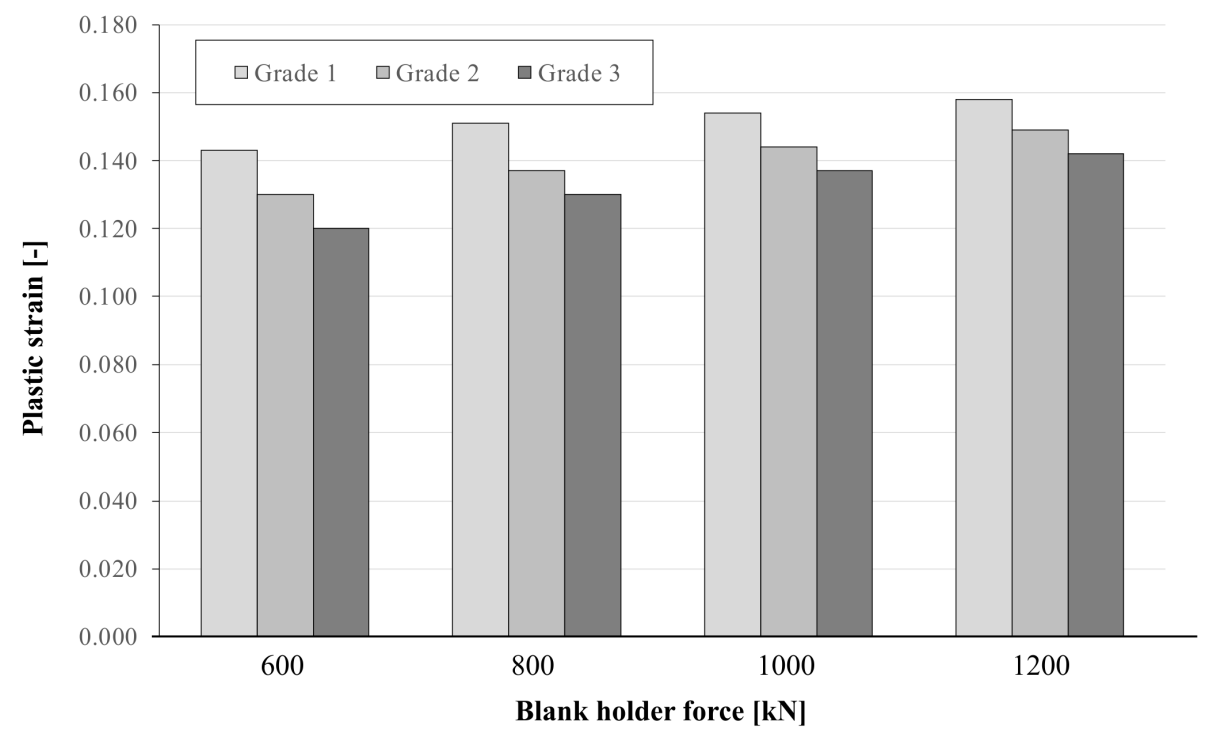

Figure 9. Maximal plastic strains in titanium panels with cross-shaped stiffeners vs blank holder force and material grade 


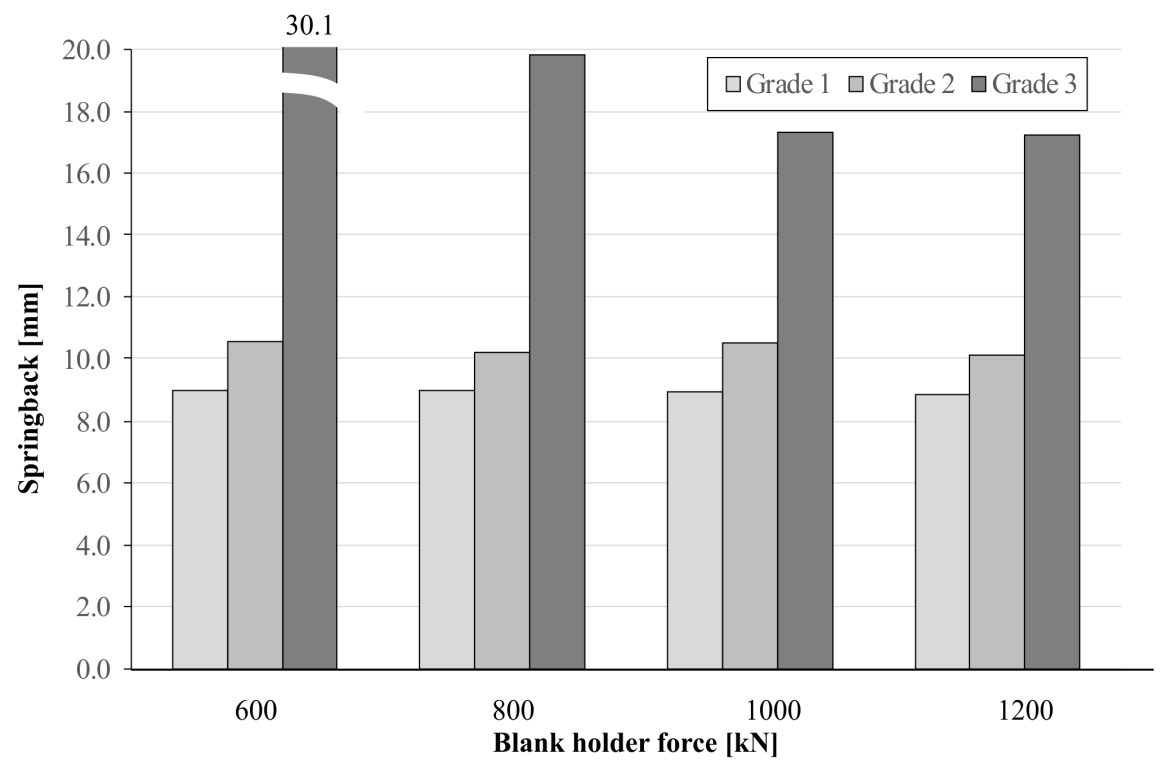

Figure 10. Spring back in titanium panels with cross-shaped stiffeners vs blank holder force and material grade

\section{CONCLUSIONS}

The numerical calculation of forming titanium panels with cross-shaped stiffeners confirm the results of research on forming titanium panels with two stiffeners, described in [26-28] that:

- the possibility of the proper forming of drawn parts depends not only on sheet drawability but also on the forming parameters, such as blank holder force and frictional coefficient

- a decrease in springback is possible when the stiffeners are formed only by material stretching without pulling the material into the die cavities

- the influence of planar anisotropy should be taken into consideration during the design and distribution of stiffeners in the panels

- such panels should be performed on doubleaction presses or special tools which at the beginning of the forming process enable firm fixing of the blank between the die and the blank holder without the possibility of the sheet sliding out from under the blank holder and then forming the stiffeners.

\section{Acknowledgements}

Financial support of Structural Funds in the Operational Programme - Innovative Economy (IE OP) financed from the European Regional Development Fund - Project "Modern material technologies in aerospace industry", No POIG.01.01.02-00-015/08-00 is gratefully acknowledged

\section{REFERENCES}

1. Adamus J. and Lacki P. Numerical analysis of forming sheet panels with stiffening ribs. Proceedings of the XIII International Conference on Computational Plasticity. Fundamentals and Applications. COMPLAS XIII, E. Oñate, D.R.J. Owen, D. Peric and M. Chiumenti (Eds). Barcelona: CIMNE 2015, 204-215.

2. Adamus J. and Lacki P. Numerical simulation of forming titanium drawn part. Meccanica 51(2), 2016, 391-400.

3. Adamus J., Dyja K. and Więckowski W. Lubricants Based on Vegetable Oils as Effective Lubricating Agents in Sheet-Titanium Forming. Key Engineering Materials 687, 2016, 163-170.

4. Adamus J., Winowiecka J. and Dyner M. Analysis of forming thin titanium panels with stiffeners, Archives of Metallurgy and Materials 62(1), 2017, 175-182.

5. Adamus J.: Applications of titanium sheets in modern building construction. Advanced Materials Research, 1020, 2014, 9-14.

6. Adamus J.: Stamping of the titanium sheets. Key Engineering Materials, 410-411, 2009, 279-288.

7. Adib A.M.L., Baptista C.A.R.P., Barboza M.J.R., Haga C. and Marques C.C.F. Aircraft engine bleed system tubes: Material and failure mode analysis. Engineering Failure Analysis 14, 2007, 1605-1617.

8. Badr O.M., Barlat F., Rolfe B., Lee M-G., Hodgson P. and Weiss M. Constitutive modelling of high strength titanium alloy Ti-6Al-4V for sheet forming applications at room temperature. International Journal of Solids and Structures 80, 2016, 334-347.

9. Boyer R.R.: Titanium for aerospace: rationale and 
application. Advanced Performance Materials 2, 1995, 349-368.

10. Boyer, R. and Williams, J. Developments in research and application in the titanium industry in the USA. Proceedings of the 12th World Conference on Titanium, Beijing, 2011, 10-19.

11. Chartrel B. and Massoni E. Deep drawing of Ti6Al4V: Experiments and modeling over a wide range of strain rates and temperatures. Key Engineering Materials, 554-557, 2013, 190-194.

12. Diamanti M.V., Del Curto B. and Pedeferri M.P. Interference Colors of thin oxide layers on titanium. Color research and application 33(3), 2008, 221-228.

13. Faller K. and Froes F.H. The use of titanium in family automobiles. Journal of Metals, 53(4), 2001, 27-28.

14. Fuji H., Takahashi K. and Yamashita Y. Application of titanium alloys for automobile parts. Nippon Steel Technical Raport no 88 July 2003, 70-75.

15. Hu Z., Wang C., Chen X. and Liu J. A novel forming method for three-dimensional thin sheet metal. Proceedings of the Institution of Mechanical Engineers, Part B: Journal of Engineering Manufacture 230(9), 2016, 1751-1755.

16. Huanga J., Zhang X., Yan W., Chena Z., Shuai X., Wang A. and Wang Y. Nanotubular topography enhances the bioactivity of titanium implants, Nanomedicine, 13(6), 2017, 1913-1923.

17. Jackson M.J., Kopac J., Balazic M., Bombac D., Brojan M. and Kosel F. Titanium and Titanium Alloy Applications in Medicine. Surgical tools and medical devices, 2nd edition, eds.: Waqar Aahmed, Mark J. Jackson. Springer International Publishing, Switzerland 2016, 475-518.

18. Kosaka Y., Faller K. and Fox S. P. Newly developed titanium alloy sheets for the exhaust systems of motorcycles and automobiles. JOM: the Journal of the Minerals, Metals \& Materials Society 5(11), 2004, 32-34.

19. Kosaka Y., Fox S. P. and Faller K., Reichmann S.H. Development of low cost titanium alloy sheet for automotive exhaust applications. Proceedings of the Minerals, Metals \& Materials Society Symposium, 2004, 67-76.
20. Marciniak J.: Biomaterials (in Polish: Biomateriały). Silesian University of Technology Publishing House, Gliwice, Poland, 2002.

21. Muzykiewicz W. Rękas A., Major R., Major B. and Kustosz R. Forming of prts of artificial cardiac chambers made of titanium sheet (in Polish: Tłoczenie elementów komory sztucznego serca $\mathrm{z}$ blachy tytanowej. Ores and metals (in Polish: Rudy i Metale) 51(4), 2006, 212-218.

22. Nakamura S. and Homma K. Durability of Titanium-Clad Steel Plates used as an Anti-Corrosion System, Structural Engineering International 10(4), 2000, 262-265.

23. Niinomi M. Mechanical properties of biomedical titanium alloys. Materials Science and Engineering A243, 1998, 231-236.

24. Niinomi M., Liu Y., Nakai M., Liu H. and Li H. Biomedical titanium alloys with Young's moduli close to that of cortical bone. Regennerative Biomaterials 3(3), 2016, 173-185.

25. Odenberger E.-L., Oldenburg M., Thilderkvist P., Stoehr T., Lechler J. and Merklein M.: Tool development based on modelling and simulation of hot sheet metal forming of Ti-6Al-4V titanium alloy. Journal of Materials Processing Technology 211, 2011, 1324-1335.

26. PamStamp 2G v. 2011. User's Guide, 2011.

27. Rey C. Orthopedic biomaterials, bioactivity, biodegradation; a physical-chemical approach. Journal of Biomechanics 31(Supl.1), 1998, 182-182.

28. Su H., Luo X-B., Chai F., Shen J-C., Sun X-J. and Lu F. Manufacturing technology and application trends of titanium clad steel plates. Journal of Iron and Steel Research, International 22(11), 2015, 977-982.

29. Wierzchoń T., Czarnowska E. and Krupa D. Surface engineering in production of titanium biomaterials (in Polish: Inżynieria powierzchni w wytwarzaniu biomateriałów tytanowych). Warsaw University of Technology Publishing House, Warsaw, Poland, 2004.

30. Zhoua Y.G., Zeng W.D. and Yu H.Q. An investigation of a new near-beta forging process for titanium alloys and its application in aviation components. Materials Science and Engineering A 393, 2005, 204-212. 